\title{
Zoster vaccination: A new opportunity for adult immunization
}

\author{
Kevin B Laupland MD MS FRCPC ${ }^{1}$, David N Fisman MD MPH FRCPC ${ }^{2}$
}

Z ostavax (Merck Frosst Canada, Inc) was granted approval for use in Canada in the summer of 2008. However, due to initial production limitations, this vaccine has only become available in September 2009 for the prevention of herpes zoster (shingles) infection in Canadian adults. Zostavax is a live, injectable, attenuated herpes zoster vaccine based on the Oka/ Merck strain that is similar to varicella vaccine with the exception that it contains an approximately 14-fold higher dose. The underlying rationale for the vaccine is to boost the normal waning of cell-mediated immunity to varicella zoster virus that occurs with aging to reduce the risk of zoster and associated complications (1).

Although a rare cause of death, zoster is an important cause of human disease and suffering among Canadian adults. A number of studies have identified an overall incidence of zoster in adults of approximately four cases per 1000 population per year and a lifetime risk of $20 \%$ to $30 \%(2-4)$. While zoster may occur at any age, there is a significant increased risk for zoster with advancing age beginning at 50 to 60 years, with a steep rise in incidence thereafter. Acute zoster may occasionally be severe, as with infections involving the eye or central nervous system, or those complicated by secondary bacterial infection. Reported rates of hospital admission in older adults may be as high as $10 \%$ (3). However, the most common complication of zoster is postherpetic neuralgia (PHN). PHN is characterized by prolonged (often defined as greater than 90 days) and debilitating neurogenic pain that persists from or follows acute zoster. This complication occurs in approximately one-fifth of adults overall but in one-third or more of octogenarians (5). PHN frequently has a major adverse impact on quality of life and treatments are of limited effectiveness (6-10). Paradoxically, models have projected that the incidence of zoster could rise over time as a result of childhood vaccination against varicella (due to the lack of boosting of immunity in adults through exposure to children with chickenpox) (11), although empirical data to date have failed to document such an effect (12).

One large phase III randomized clinical trial, The Shingles Prevention Study, evaluated the efficacy of zoster vaccination (13). In this trial, nearly 40,000 healthy adults aged 60 years or older with a prior history of chickenpox (or residence in the continental United States for greater than 30 years), were randomized to a single subcutaneous injection of either zoster vaccine or placebo (13). Subjects were followed for a mean of 3.1 years and assessed for the primary end point of herpes zoster burden of illness as determined using a previously validated scale for measurement of health-related quality of life (7).
Herpes zoster burden of illness scores were significantly reduced in the zoster vaccine group as compared with placebo (2.21 versus $5.68 ; \mathrm{P}<0.001$ ), and both duration and severity of zoster were reduced in vaccine recipients. Overall vaccine efficacy was $51 \%$ for confirmed zoster and $67 \%$ for PHN; burden of illness scores were also reduced by $61 \%$ in vaccinees. Although mild injection site reactions were more common in vaccine recipients, the vaccine was safe and generally well-tolerated.

All Canadian adults are currently recommended to have immunity (either by previous natural infection or by vaccination) to tetanus, diphtheria, measles, mumps, rubella, pertussis and varicella $(14,15)$. While rates of immunity in Canadian adults are suboptimal, rates of these diseases are generally low and may reflect, at least in part, high rates of childhood immunization with a degree of resultant herd immunity. In addition to these routine vaccines, some vaccines are recommended in a subset of adults. Influenza vaccination is widely recommended for adults but a particular focus is in those with conditions associated with increased risk for complications (16). Pneumococcal polysaccharide vaccine is recommended for adults older than 65 years of age and those with health conditions associated with an increased risk of severe pneumococcal disease (17). There are also a number of travel-recommended vaccines, and more recently the use of human papilloma virus vaccine has been recommended for certain adults (18).

Will the zoster vaccine change the way we think about and/ or approach routine immunization of Canadian adults?

A unique aspect of the zoster vaccine is that it is very clearly an adult vaccine. It is only indicated for those at least 50 to 60 years of age and is not recommended for younger age groups. This vaccine is unlikely to benefit children; this is especially true for individuals who have been vaccinated for chickenpox and have not had wild-type varicella zoster virus infection (and hence have negligible risk for wild-type zoster). The concept of a vaccine reserved for adults is contrary to our vast experience with immunization to date. Traditionally, immunization of adults has largely been an extension of childhood immunization programs.

Second, the zoster vaccine may be viewed as a 'quality of life vaccine'. This is by virtue of the fact that its major expected benefit is in reducing the incidence of the non-life-, limb- or sight-threatening complication of PHN. This vaccine does not have any influence on mortality; the overall mortality observed among vaccinated subjects (14 deaths; $4.1 \%$ ) was the same as for those who received placebo (16 deaths; $4.1 \%$ ) in The

\footnotetext{
${ }^{1}$ Departments of Medicine, Critical Care Medicine, Pathology and Laboratory Medicine, Centre for Antimicrobial Resistance, University of Calgary, Calgary Laboratory Services, Calgary Health Region, Calgary, Alberta; ${ }^{2}$ The Research Institute of the Hospital for Sick Children, University of Toronto, Ontario Agency for Health Protection and Promotion, Toronto, Ontario

Correspondence: Dr Kevin B Laupland, Room 719, North Tower, Foothills Medical Centre, 1403-29th Street Northwest, Calgary, Alberta

T2N 2T9. Telephone 403-944-5808, fax 403-944-3199, email Kevin.Laupland@albertahealthservices.ca
} 
Shingles Prevention Study (13). The concept of a vaccine that principally protects quality of life is in contrast to the vast majority of traditional vaccinations where the goal is prevention of virulent diseases with high case-fatality rates (eg, tetanus, diphtheria or smallpox) or those associated with serious and frequently disabling medical complications (eg, rubella, polio).

Third, zoster vaccination may only be expected to have a major benefit to the vaccinated individual, and will be unlikely to have a major effect on the population at large via secondary 'herd' effects. While traditionally the primary objective of immunization is benefit to the individual, high levels of immunization against extremely transmissible diseases also prevents disease acquisition by those who do not receive the vaccine in question. Such herd effects were demonstrated with the introduction of infant conjugate pneumococcal vaccine, which decreased the incidence of disease in unvaccinated adults, and have also been seen in the reduction of pertussis in the very young through booster vaccination in adolescents and adults, and in the reduction of illness among hospitalized patients and residents of nursing homes when health care workers are immunized $(14,19,20)$. However, while primary varicella is a highly contagious, airborne infection, zoster is not. Consequently, it is unlikely that zoster vaccination will result in important health effects in nonvaccinated individuals.

Finally, we are accustomed to vaccines as interventions with high efficacy, achieved at relatively low cost (although the efficacies of influenza and polysaccharide pneumococcal vaccines in older adults have been questioned). Nonetheless, whether adults will accept a vaccine that has only an approximate $50 \%$ to $60 \%$ efficacy in preventing zoster remains to be determined. Furthermore, the cost of the zoster vaccine will likely be a major consideration in its use. Several economic evaluations of zoster vaccination have placed the 'cost-utility ratio' (dollars spent per quality-adjusted life-year [QALY] gained) with zoster vaccination at $\$ 25,000$ to $\$ 50,000$ per QALY (21-24). One Canadian economic evaluation projected that, at $\$ 150$ per dose, vaccinating 65 year olds would cost $\$ 33,000$ per QALY gained, and for those between 65 and 75 years of age below $\$ 40,000$ per QALY gained (21). This would be classed by health economists as a 'highly cost-effective' health intervention in a country as wealthy as Canada (health interventions warrant this designation if a QALY can be purchased at less than per-capita gross national income), this is nonetheless a higher cost per QALY than has been associated with many previously introduced vaccines. It remains to be seen whether the cost-effectiveness of this vaccine justifies the allocation of new public funds to pay for a widespread program, or whether individual Canadian adults find it desirable to pay out-of-pocket for such a vaccine.

In summary, the availability of the zoster vaccine will inevitably influence our views and experiences with immunization. If it is widely adopted, we are likely to observe some degree of reduction in the overall burden of zoster and its complications in Canadian adults. Perhaps more importantly, zoster vaccine may represent a harbinger of an increasing tendency for emerging vaccines to move away from traditional frameworks with respect to target populations, objectives of vaccination programs, and benchmarks that define health-economic attractiveness.

\section{REFERENCES}

1. Oxman MN. Immunization to reduce the frequency and severity of herpes zoster and its complications. Neurology 1995;45(Suppl 8):S41-6.

2. Russell ML, Schopflocher DP, Svenson L, Virani SN. Secular trends in the epidemiology of shingles in Alberta. Epidemiol Infect 2007;135:908-13.

3. Brisson M, Edmunds WJ, Law B, et al. Epidemiology of varicella zoster virus infection in Canada and the United Kingdom. Epidemiol Infect 2001;127:305-14.

4. Edgar BL, Galanis E, Kay C, Skowronski D, Naus M, Patrick D. The burden of varicella and zoster in British Columbia 1994-2003: Baseline assessment prior to universal vaccination. Can Commun Dis Rep 2007;33:1-15.

5. Yawn BP, Saddier P, Wollan PC, St Sauver JL, Kurland MJ, Sy LS. A population-based study of the incidence and complication rates of herpes zoster before zoster vaccine introduction. Mayo Clin Proc 2007;82:1341-9.

6. Lieu TA, Ortega-Sanchez I, Ray GT, et al. Community and patient values for preventing herpes zoster. Pharmacoeconomics 2008;26:235-49.

7. Coplan PM, Schmader K, Nikas A, et al. Development of a measure of the burden of pain due to herpes zoster and postherpetic neuralgia for prevention trials: Adaptation of the brief pain inventory. J Pain 2004;5:344-56.

8. Lydick E, Epstein RS, Himmelberger D, White CJ. Herpes zoster and quality of life: A self-limited disease with severe impact. Neurology 1995;45(Suppl 8):S52-3.

9. Pavan-Langston D. Herpes zoster antivirals and pain management. Ophthalmology 2008;115(2 Suppl):S13-20.

10. Dworkin RH, Gnann JW Jr, Oaklander AL, Raja SN, Schmader KE, Whitley RJ. Diagnosis and assessment of pain associated with herpes zoster and postherpetic neuralgia. J Pain 2008;9(Suppl 1):S37-44.

11. Brisson M, Edmunds WJ, Gay NJ.Varicella vaccination: Impact of vaccine efficacy on the epidemiology of VZV. J Med Virol 2003;70(Suppl 1):S31-7.

12. Kwong JC, Tanuseputro P, Zagorski B, Moineddin R, Chan KJ. Impact of varicella vaccination on health care outcomes in Ontario, Canada: Effect of a publicly funded program? Vaccine 2008;26:6006-12.

13. Oxman MN, Levin MJ, Johnson GR, et al. A vaccine to prevent herpes zoster and postherpetic neuralgia in older adults. N Engl J Med 2005;352:2271-84.

14. Canadian Immunization Guide 2006. National Advisory Committee on Immunization. Public Health Agency of Canada. <www.naci.gc.ca> (Version current June 18, 2009).

15. Parkins MD, McNeil SA, Laupland KB. Routine immunization of adults in Canada: Review of the epidemiology of vaccine-preventable diseases and current recommendations for primary prevention. Can J Infect Dis Med Microbiol 2009;20:e81-90.

16. Statement on influenza vaccination for the 2008-2009 season. An Advisory Committee Statement (ACS). Can Commun Dis Rep 2008;34(ACS-3):1-46.

17. Statement on the recommended use of pneumococcal 23-valent polysaccharide vaccine in homeless persons and injection drug users. An Advisory Committee Statement (ACS). Can Commun Dis Rep 2008;34(ACS-5):1-12.

18. Statement on human papillomavirus vaccine. An Advisory Committee Statement (ACS). Can Commun Dis Rep 2007;33(ACS-2):1-31.

19. Kellner JD, Vanderkooi OG, Macdonald J, Church DL, Tyrrell GJ, Scheifele DW. Changing Epidemiology of Invasive Pneumococcal Disease in Canada, 1998-2007: Update from the Calgary-Area Streptococcus pneumoniae Research (CASPER) Study. Clin Infect Dis 2009;49:205-12.

20. De Serres G. An Advisory Committee Statement (ASC). National Advisory Committee on Immunization (NACI). Statement on adult/ adolescent formulation of combined acellular pertussis, tetanus, and diphtheria vaccine. Can Commun Dis Rep 2000;26:1-8.

21. Brisson M, Pellissier JM, Camden S, Quach C, De Wals P. The potential cost-effectiveness of vaccination against herpes zoster and post-herpetic neuralgia. Hum Vaccin 2008;4(3). [Epub ahead of print]

22. Rothberg MB, Virapongse A, Smith KJ. Cost-effectiveness of a vaccine to prevent herpes zoster and postherpetic neuralgia in older adults. Clin Infect Dis 2007;44:1280-8.

23. Pellissier JM, Brisson M, Levin MJ. Evaluation of the cost-effectiveness in the United States of a vaccine to prevent herpes zoster and postherpetic neuralgia in older adults. Vaccine 2007;25:8326-37.

24. van Hoek AJ, Gay N, Melegaro A, Opstelten W, Edmunds WJ. Estimating the cost-effectiveness of vaccination against herpes zoster in England and Wales. Vaccine 2009;27:1454-67. 


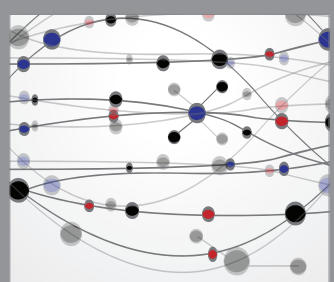

The Scientific World Journal
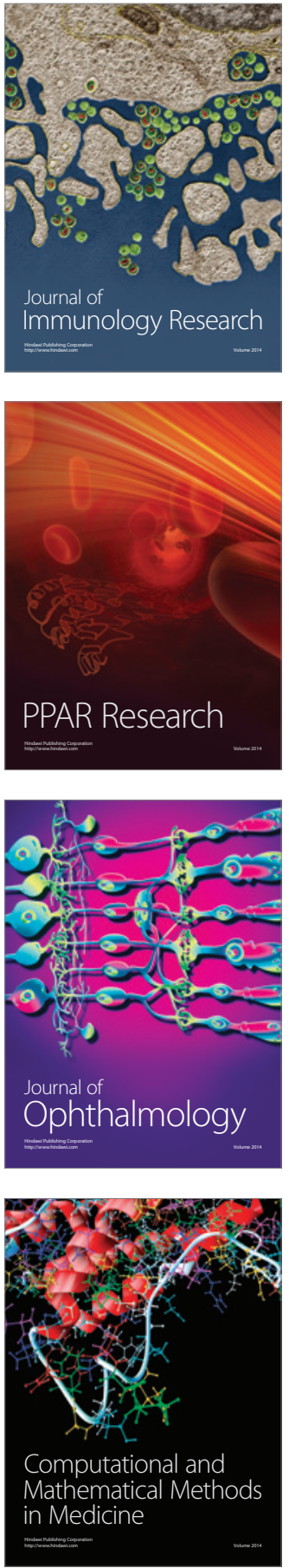

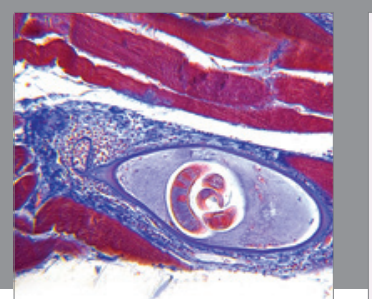

Gastroenterology Research and Practice

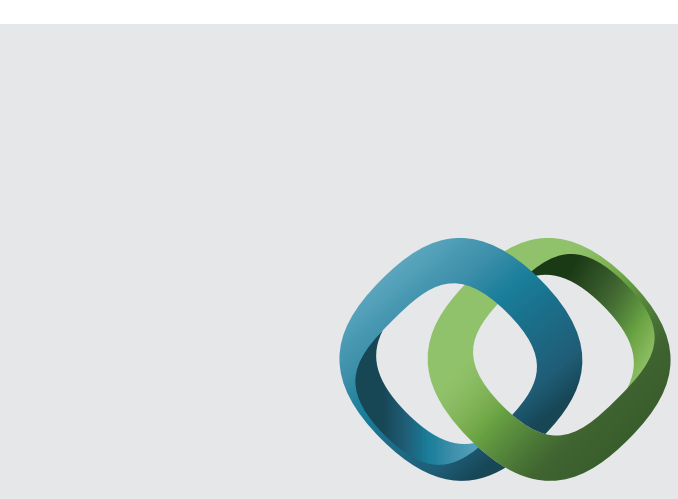

\section{Hindawi}

Submit your manuscripts at

http://www.hindawi.com
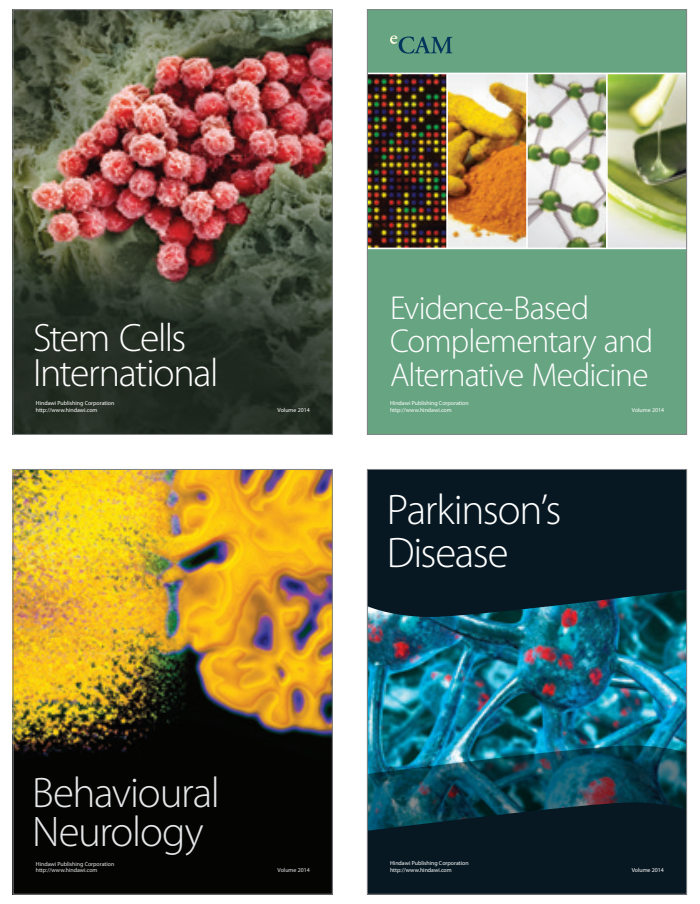
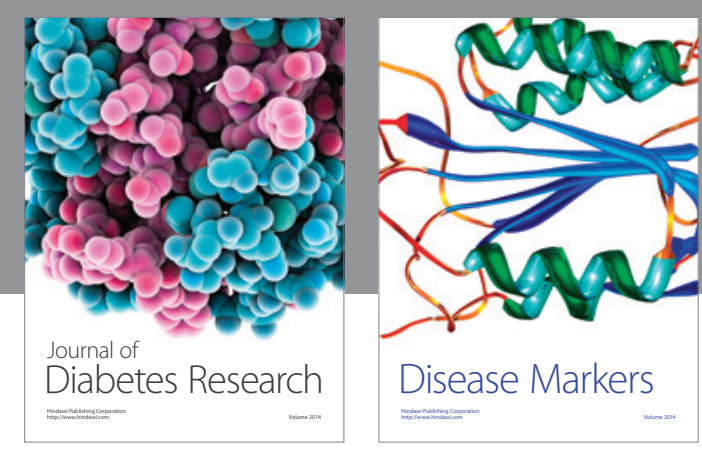

Disease Markers
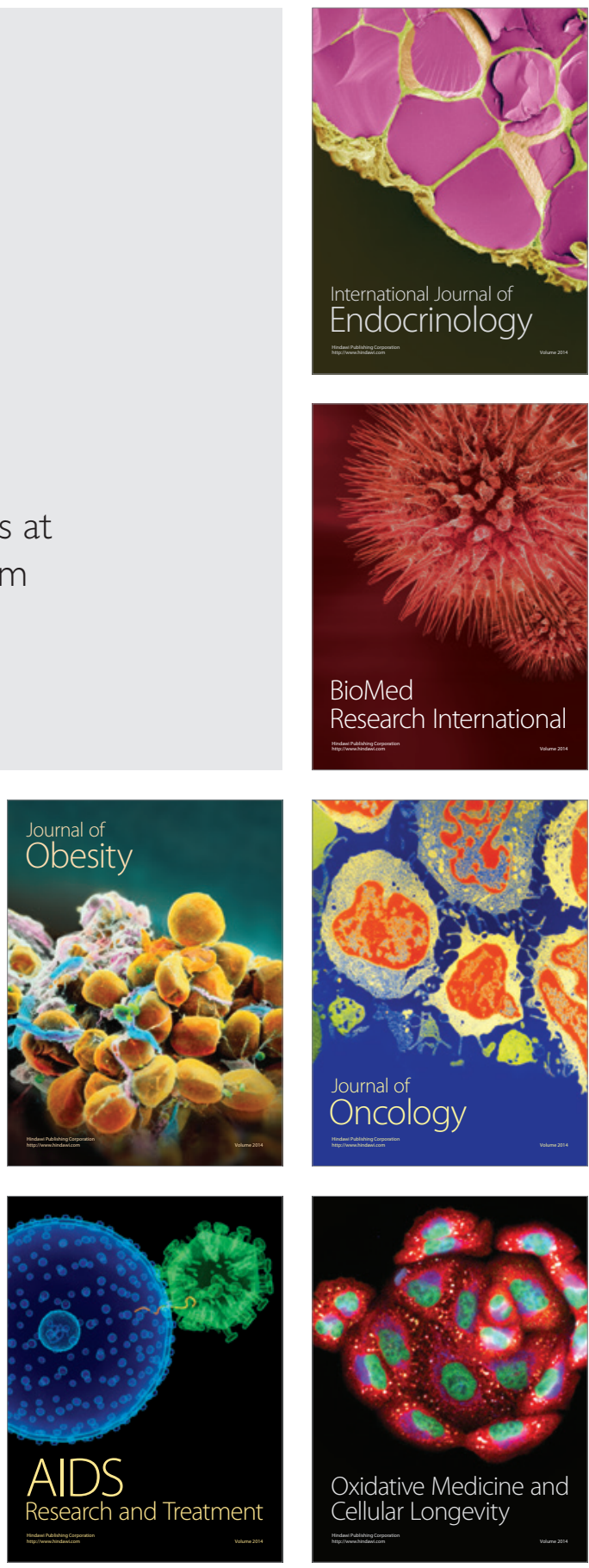